\title{
GAYA KEPEMIMPINAN PARTISIPATIF DALAM UPAYA MENINGKATKAN PROFESIONAL GURU
}

\author{
Aditya Wahyu Permana \\ Karwanto \\ Jurusan Manajemen Pendidikan, Fakultas Ilmu Pendidikan, Universitas Negeri Surabaya \\ Email: adityapermana16010714012@mhs.unesa.ac.id
}

\begin{abstract}
The purpose of this scientific article is to determine participatory leadership styles in an effort to improve teacher professionalism. This article uses literature / literature studies, namely by interpreting several national and international journals so that in obtaining data through text studies then it is analyzed using content analysis. The result of this article is that a participatory leadership style in an effort to improve teacher professionalism is the existence of suggestions from subordinates in the decision-making process. Thus, their subordinates feel more valued by their superiors because they are considered capable of playing a role in decision making. With a leadership style like this, the relationship between the leader and his subordinates will be well maintained.
\end{abstract}

Keywords : leadership, participatory, teacher professionalsme

\begin{abstract}
Abstrak: Tujuan artikel ilmiah ini untuk mengetahui gaya kepemimpinan partisipatif dalam upaya meningkatkan profesional guru. Artikel ini menggunakan studi literatur / kepustakaan yaitu dengan cara mengartikan beberapa jurnal nasional maupun internasional sehingga dalam memperoleh data melalui kajian teks kemudian dianalisis dengan menggunakan analisis isi. Hasil dari artikel ini adalah gaya kepemimpinan partisipatif dalam upaya meningkatkan profesional guru adalah adanya saran-saran dari bawahan dalam proses pengambilan keputusan. Dengan demikian, bawahannya merasa lebih dihargai oleh atasannya karena mereka dianggap mampu berperan dalam pengambilan keputusan. Dengan gaya kepemimpinan seperti ini, hubungan antara pemimpin dengan bawahan akan terjaga dengan baik.
\end{abstract}

Kata kunci: kepemimpinan, partisipatif, profesional guru

Guru merupakan semua orang yang bertanggung jawab terhadap pendidikan muridmurid baik di sekolah maupun di luar sekolah. Maka seorang guru harus menguasai berbagai kompetensi baik pedagogis, kepribadian, sosial kemasyarakatan maupun profesional. Berdasarkan hasil studi pendahuluan menunjukkan masih kurangnya gaya partisipatif yang digunakan untuk meningkatkan profesionalisme guru. Untuk menjadi seorang guru diperlukan syarat-syarat khusus, sebagai guru yang profesional harus menguasai benar-benar pendidikan dan pengajaran dengan berbagai ilmu pengetahuan lainnya (Heriyansyah, 2018). Menurut Hasanaah, (2012) menjelaskan bahwa profesionalisme guru merupakan atribut dan kompetensi seseorang yang didapat dari suatu proses pendidikan yang secara sengaja dirancang khusus (bukan hanya pelatihan), dan seorang profesionalisme guru itu seorang profesional membantu memecahkan masalah yang dihadapi orang lain yang memerlukan layanannya. Tilaar (Berdiyana, (2019) menjelaskan bahwa pula seorang profesional seharusnya menjelaskan pekerjaannya sesuai dengan ketentuan profesi yang mempunyai kompetensi serta sikap yang sesuai dengan tuntutan profesi yang dilakukuan. Menurut (Hargreaves, 2000) profesionalisme guru adalah bagaimana cara mereka berperilaku dan menerapkan pengetahuan dan keterampilan mereka untuk meningkatkan profesionalisme. 
Kunandar (2007:51) berpendapat kompetensi yang wajib dimiliki oleh guru pada aspek profesionalisme meliputi beberapa hal yaitu: (a) Kompetensi intelektual, adalah beberapa perangkat pengaturan yang ada pada diri seseorang; (b) Kompetensi fisik akan mendukung pelaksanaan guru untuk menangani situasi yang ada; (c) Kompetensi pribadi adalah sikap yang berhubungan dengan kemampuan individu untuk mewujudkan pribadinya sendiri dalam melaksanakan transformasi, identitas, dan pemahaman; (d) Kompetensi sosial adalah perilaku yang terkait dengan pemahaman diri yang terpisahkan dalam interaksi efektif; (e) Kompetensi spiritual, adalah pengalaman, penghayatan dan pemahaman dalam kaidah keagamaan.

Indikator profesional guru menurut Maister (1997:136-137) terdiri dari beberapa macam indikator sebagai berikut: (a) Menguasai mata pelajaran secara menyeluruh dalam beberapa standar isi dalam program satuan pendidikan; (b) Menguasai suatu konsep, metode dalam keilmuan, teknologi, seni yang sesuai secara konseptual dan beberapa mata pelajaran yang diampu; (c) Menguasai standar kompetensi baik dalam kompetensi dasar pada mata pelajaran yang diampu; (d) Dapat mengembangkan profesional kelanjutan melalui tindakan reflektif ; (e) Memanfaatkan teknologi komunikasi dan informasi untuk berkomunikasi dan mengembangkan diri; (f) Mengembangkan materi pembelajaran secara kreatif.

Kepemimpinan secara singkat dapat dipahami sebagai proses yang berpengaruh pada kegiatan organisasi atau kelompok untuk mencapai tujuan organisasi dan kelompok (Rahmi, 2014:16). Kepemimpinan selain membantu tercapainya tujuan dari organisasi dan kelompok juga sangat membantu pengelolaan dari sebuah organisasi atau kelompok, hal ini dapat kita lihat dalam bidangbidang di masyarakat seperti pendidikan, ekonomi, politik dan sebagainya. Terlebih dalam hal pendidikan kepemimpinan masuk dalam unsur yang tak bisa dipisahkan dari peyelenggaraan pendidikan karena memliki peran sangat penting bagi sekolah, hal ini sesuai dengan pendapat Mintzerberg (Basari \& Tatang, 2015:19) kepemimpinan memiliki peran sebagai peran antar pribadi, peran informasional, peran juru bicara, dan peran pengambilan keputusan.
Karakteristik gaya kepemimpinan yang beranekaragam dapat mempengaruhi sikap bawahan. Peranan itu sebagai berikut: (1) Mempunyai keaktifan dalam organisasi; (2) Dapat mengutamakan kepentingan kegiatan; (3) Mampu untuk bekerjasama dalam setiap hubungan kelompok di organiasi lainnya; (4) Membuat hubungan yang baik antara staf dalam organisasi; (5) Bisa membuat keuntungan dalam hubungan kelompok di dalam tubuh organisasi; (6) Mencontohkan teknik pelaksanaan program organisasi terhadap bawahannya.

Untuk meningkatkan profesionalisme guru perlu dukungan dari berbagai pihak-pihak meliputi peserta didik, pendidik, kepala sekolah dan orang tua. Sebagai contoh pentingnya kelibatan seluruh warga sekolah dalam merumuskan kebijakan karena nantinya akan berdampak bagi penyelenggaraan pendidikan di lingkungan sekolah tersebut. Dan juga masalah kesejahteraan guru penting untuk diperhatikan oleh pemegang kepemimpinan, karena jika kesejahteraan guru tidak terjamin akan berdampak kepada proses pembelajaran. Hal tersebut sesuai dengan Undang-undang atau peraturaan.

Kepemimpinan partisipatif memberikan berbagai manfaat, akan tetapi manfaat tersebut bergantung pada siapa partisipannya. Hal tersebut dipengaruhi oleh apa yang mereka miliki, dan aspek lain dalam pengambilan keputusan. Terdapat empat manfaat potensial meliputi kualitas keputusan yang meningkat oleh para partisipan, kepuasaan yang tinggi oleh partisipan, kepuasan lebih atas proses keputusan, dan pengembangan keterampilan membuat keputusan (Yukl, 2015:102). Menurut Somech dan Wenderow (2006) gaya kepimimpinan partisipatif didefinisikan sebagai pengambilan keputusan bersama antara atasan dengan bawahan.

Kepemimpinan partisipatif dapat diartikan sebagai seorang pemimpin yang mengikutsertakan bawahannya untuk pengambilan keputusan (Mulyasa, 2006: 116). Kepemimpinan partisipatif juga mengikutkan bawahannya saling tukar menukar ide dalam pemecahan masalah dan pembuatan keputusan untuk mewujudkan cita-cita sekolah (Thoha, 2012: 67).

Hasibuan (2016:171) mengemukakan tiga indikator gaya kepemimpinan partisipatif, yaitu: (a) wewenang pimpinan tidak mutlak; (b) keputusan dibuat bersama antara pimpinan 
dan bawahan; (c) banyak kesempatan bagi bawahan untuk menyampaikan saran dan pendapat.

Salah satu pencapaian dari gaya kepimpinan partisipatif adalah kepuasan kerja untuk gaya kepemimpinan tersebut berperan sangat penting untuk mempengaruhi kepuasan kerja yang baik.

Berdasarkan berbagai penelitian gaya kepemimpinan dan profesionalisme guru sepengetahuan peneliti belum ada studi literatur tentang gaya kepemimpinan partisipatif dan profesionalisme guru.

Tujuan dari studi literatur ini untuk mengetahui perbandingan gaya kepemimpinan partisipatif yang dijalankan oleh kepala sekolah yang bertujuan untuk meningkatkan profesionalime terhadap guru.

\section{METODE}

Metode penelitian ini menggunakan desain penelitian dengan studi kepustakaan atau studi literatur. Data penelitian dikumpulkan melalui kajian teks kemudian dianalisis dengan teknik analisis isi. Langkah-langkahnya yaitu. Pertama, data-data yang telah terkumpul diklasifikasi berdasarkan masalah yang dikaji. Kedua, data-data yang dikaji secara kualitatif dianalisis dengan menggunakan analisis isi. Ketiga, berdasarkan hasil analisis dan interpretasi data, penulis mengambil simpulan yang dilengkapi dengan saran-saran.

Tabel 1. Studi literatur artikel jurnal

\begin{tabular}{|c|c|c|c|c|}
\hline No. & Penulis & $\begin{array}{c}\text { Judul } \\
\text { penelitian }\end{array}$ & $\begin{array}{c}\text { Metode } \\
\text { Peneliti } \\
\text { an }\end{array}$ & $\begin{array}{l}\text { Instrum } \\
\text { en }\end{array}$ \\
\hline 1 & $\begin{array}{l}\text { Hyeo, } \\
\text { Young. } \\
2020 . \\
\text { Departm } \\
\text { ent of } \\
\text { Educatio } \\
\mathrm{n} \text {, } \\
\text { College } \\
\text { of } \\
\text { Educatio } \\
\text { n, } \\
\text { Gyeongs } \\
\text { ang }\end{array}$ & $\begin{array}{l}\text { The effects } \\
\text { of } \\
\text { distributed } \\
\text { leadership } \\
\text { on teacher } \\
\text { professional } \\
\text { ism:The } \\
\text { case of } \\
\text { Korean } \\
\text { middle } \\
\text { schools }\end{array}$ & $\begin{array}{l}\text { Metode } \\
\text { penelitia } \\
\mathrm{n} \\
\text { kualitatif }\end{array}$ & $\begin{array}{l}\text { Observa } \\
\text { si guru. }\end{array}$ \\
\hline 2 & $\begin{array}{l}\text { Moham } \\
\text { ad } \\
\text { Nurman, } \\
\text { Yovitha } \\
\text { Yuliejant } \\
\text { iningsih, }\end{array}$ & $\begin{array}{l}\text { Pengaruh } \\
\text { kepemimpin } \\
\text { an } \\
\text { Partisiptif } \\
\text { kepala } \\
\text { sekkolah }\end{array}$ & $\begin{array}{l}\text { Metode } \\
\text { penelitia } \\
\text { n } \\
\text { kuantitati } \\
\text { f }\end{array}$ & $\begin{array}{l}\text { Observa } \\
\text { si }\end{array}$ \\
\hline
\end{tabular}

\begin{tabular}{|c|c|c|c|c|}
\hline & $\begin{array}{l}\text { Fenny } \\
\text { Roshay } \\
\text { anti, } \\
2018 \\
\text { (Indone } \\
\text { sia) }\end{array}$ & $\begin{array}{l}\text { dan } \\
\text { kompetensi } \\
\text { guru } \\
\text { terhadap } \\
\text { mutu } \\
\text { sekolah } \\
\text { SMP } \\
\text { NEGERI DI } \\
\text { KECAMAT } \\
\text { AN } \\
\text { BUMIAYU } \\
\text { KABUPATE } \\
\text { N BREBES }\end{array}$ & & \\
\hline 3 & $\begin{array}{l}\mathrm{H} . \\
\text { Muham } \\
\text { ad Alil, } \\
\text { Agus } \\
\text { Ramada } \\
\text { ni, } \\
\text { Hamids } \\
\text { yukurie, } \\
2016 \\
\text { (Indone } \\
\text { sia) }\end{array}$ & $\begin{array}{l}\text { Pengaruh } \\
\text { kepemimpin } \\
\text { an } \\
\text { partisipatif } \\
\text { kepala } \\
\text { sekolaj dan } \\
\text { iklim kerja } \\
\text { terhadap } \\
\text { kinerja guru } \\
\text { SMP } \\
\text { NEGERI } 1 \\
\text { KOTA } \\
\text { MATARAM }\end{array}$ & $\begin{array}{l}\text { Pendeka } \\
\text { tan } \\
\text { deskriptif } \\
\text { kuantitati } \\
f\end{array}$ & $\begin{array}{l}\text { Observa } \\
\text { si dan } \\
\text { kuesione } \\
r\end{array}$ \\
\hline 4 & $\begin{array}{l}\text { Tarhid, } \\
2018\end{array}$ & $\begin{array}{l}\text { Kepemimpi } \\
\text { nan Kepala } \\
\text { Sekolah } \\
\text { dalam } \\
\text { Meningkatk } \\
\text { an } \\
\text { Profesionali } \\
\text { sme Guru }\end{array}$ & $\begin{array}{l}\text { Metode } \\
\text { literatur }\end{array}$ & Artikel \\
\hline 5 & $\begin{array}{l}\text { Sipayun } \\
\text { g, } 2019\end{array}$ & $\begin{array}{l}\text { Pengaruh } \\
\text { Gaya } \\
\text { Kepemimpi } \\
\text { nan Kepala } \\
\text { Sekolah } \\
\text { Dalam } \\
\text { Meningkatk } \\
\text { an } \\
\text { Kreativitas } \\
\text { Guru Di } \\
\text { Sma St. } \\
\text { Maria } \\
\text { Medan }\end{array}$ & \begin{tabular}{|l} 
Metode \\
Kualitatif \\
dan \\
kuantitati \\
$\mathrm{f}$
\end{tabular} & $\begin{array}{l}\text { Wawanc } \\
\text { ara dan } \\
\text { kuesione } \\
r\end{array}$ \\
\hline 6 & $\begin{array}{l}\text { Winarsi } \\
\text { h, } 2018\end{array}$ & $\begin{array}{l}\text { Gaya } \\
\text { Kepemimpi } \\
\text { nan Kepala } \\
\text { Sekolah } \\
\text { dalam } \\
\text { Meningkatk } \\
\text { an Kinerja } \\
\text { Guru }\end{array}$ & Literatur & $\begin{array}{l}\text { Artikel } \\
\text { penelitia } \\
\mathrm{n}\end{array}$ \\
\hline 7 & $\begin{array}{l}\text { Putri , } \\
2019\end{array}$ & $\begin{array}{l}\text { Meningkatk } \\
\text { an } \\
\text { Profesionali } \\
\text { sme Guru } \\
\text { Sebagai }\end{array}$ & Literatur & $\begin{array}{l}\text { Artikel } \\
\text { Penelitia } \\
\mathrm{n}\end{array}$ \\
\hline
\end{tabular}




\begin{tabular}{|c|c|c|c|c|}
\hline & & $\begin{array}{l}\text { Aktor } \\
\text { Utama } \\
\text { Dalam } \\
\text { Dunia } \\
\text { Pendidikan }\end{array}$ & & \\
\hline 8 & $\begin{array}{l}\text { Septiani } \\
\text {, } 2019\end{array}$ & $\begin{array}{l}\text { Gaya } \\
\text { Kepemimpi } \\
\text { nan } \\
\text { Pendidikan }\end{array}$ & Literatur & $\begin{array}{l}\text { Artikel } \\
\text { Penelitia } \\
n\end{array}$ \\
\hline 9 & $\begin{array}{l}\text { Arum, } \\
2007\end{array}$ & $\begin{array}{l}\text { Upaya } \\
\text { Meningkatk } \\
\text { an } \\
\text { Profesionali } \\
\text { sme Guru } \\
\text { Berlandask } \\
\text { an IImu } \\
\text { Pendidikan } \\
\text { Dalam } \\
\text { Mencerdask } \\
\text { an } \\
\text { Kehidupan } \\
\text { Bangsa }\end{array}$ & Literatur & $\begin{array}{l}\text { Artikel } \\
\text { penelitia } \\
\text { n, Studi } \\
\text { dokume } \\
\text { ntasi }\end{array}$ \\
\hline 10 & $\begin{array}{l}\text { Naim, } \\
2017\end{array}$ & $\begin{array}{l}\text { Profesionali } \\
\text { sme } \\
\text { Kepemimpi } \\
\text { nan Kepala } \\
\text { Sekolah } \\
\text { Dan Kinerja } \\
\text { Guru } \\
\text { Dalam } \\
\text { Peningkata } \\
\text { n } \\
\text { Prestasi } \\
\text { Belajar } \\
\text { Siswa. }\end{array}$ & $\begin{array}{l}\text { Metode } \\
\text { kualitatif }\end{array}$ & $\begin{array}{l}\text { Observa } \\
\text { si, } \\
\text { wawanc } \\
\text { aram } \\
\text { dan } \\
\text { dokume } \\
\text { ntasi }\end{array}$ \\
\hline 11 & $\begin{array}{l}\text { Puspiani } \\
, 2017\end{array}$ & $\begin{array}{l}\text { Upaya } \\
\text { Kepala } \\
\text { Sekolah } \\
\text { Dalam } \\
\text { Meningkatk } \\
\text { an } \\
\text { Profesionali } \\
\text { sme Guru } \\
\text { Fiqih Di } \\
\text { Madrasah } \\
\text { lbtidaiyah } \\
\text { Darul Fikri } \\
\text { Tahun } \\
\text { 2016-2017 }\end{array}$ & $\begin{array}{l}\text { Metode } \\
\text { Kualitatif }\end{array}$ & $\begin{array}{l}\text { Observa } \\
\text { si, } \\
\text { Wawanc } \\
\text { ara dan } \\
\text { Studi } \\
\text { dokume } \\
\text { ntasi }\end{array}$ \\
\hline 12 & $\begin{array}{l}\text { Ruslan, } \\
2020\end{array}$ & $\begin{array}{l}\text { The } \\
\text { Influence of } \\
\text { Principal's } \\
\text { Situational } \\
\text { Leadership } \\
\text { and } \\
\text { Teacher's } \\
\text { Professiona } \\
\text { lism on } \\
\text { Teacher's } \\
\text { Performanc }\end{array}$ & $\begin{array}{l}\text { Metode } \\
\text { Kuantitat } \\
\text { if }\end{array}$ & $\begin{array}{l}\text { Kuesion } \\
\text { er dan } \\
\text { wawanc } \\
\text { ara }\end{array}$ \\
\hline
\end{tabular}

\begin{tabular}{|c|c|c|c|c|}
\hline & & $e$ & & \\
\hline 13 & $\begin{array}{l}\text { Gaduso } \\
\text { va, } 2019\end{array}$ & $\begin{array}{l}\text { Teachers' } \\
\text { Professiona } \\
\text { I } \\
\text { Competenc } \\
\text { e and Their } \\
\text { Evaluation }\end{array}$ & $\begin{array}{l}\text { Metode } \\
\text { Kuantitat } \\
\text { if }\end{array}$ & $\begin{array}{l}\text { Dokume } \\
\mathrm{n} \text {, dan } \\
\text { wawanc } \\
\text { ara }\end{array}$ \\
\hline 14 & $\begin{array}{l}\text { Gultom, } \\
2018\end{array}$ & $\begin{array}{l}\text { Effect of } \\
\text { Democratic } \\
\text { Leadership } \\
\text { Style and } \\
\text { Bureaucrati } \\
\text { c } \\
\text { Leadership } \\
\text { Style } \\
\text { against } \\
\text { Teacher } \\
\text { Work } \\
\text { Motivation } \\
\text { in Dolok } \\
\text { Batu } \\
\text { Naggar } \\
\text { State } 1 \\
\text { State } \\
\text { School }\end{array}$ & $\begin{array}{l}\text { Metode } \\
\text { Kuantitat } \\
\text { if }\end{array}$ & $\begin{array}{l}\text { Kuesion } \\
\text { er dan } \\
\text { wawanc } \\
\text { ara }\end{array}$ \\
\hline 15 & $\begin{array}{l}\text { Burhanu } \\
\text { din, } \\
2017\end{array}$ & $\begin{array}{l}\text { The Roles } \\
\text { of } \\
\text { Principals } \\
\text { in } \\
\text { Encreasing } \\
\text { Education } \\
\text { Quality by } \\
\text { Developing } \\
\text { Teacher } \\
\text { Profesionali } \\
\text { sm }\end{array}$ & $\begin{array}{l}\text { Metode } \\
\text { Kualitatif }\end{array}$ & $\begin{array}{l}\text { Artikel } \\
\text { penelitia } \\
\mathrm{n}, \\
\text { wawanc } \\
\text { ara , } \\
\text { studi } \\
\text { dokume } \\
\text { ntasi }\end{array}$ \\
\hline 16 & $\begin{array}{l}\text { Suhanji, } \\
2016\end{array}$ & $\begin{array}{l}\text { Synergy of } \\
\text { Teacher } \\
\text { Profesionali } \\
\text { sm } \\
\text { Developme } \\
\text { nt of The } \\
\text { Quality of } \\
\text { Education }\end{array}$ & Literatur & Artikel \\
\hline 17 & $\begin{array}{l}\text { Segredo } \\
, 2014\end{array}$ & $\begin{array}{l}\text { The } \\
\text { Relationshi } \\
\text { ps Between } \\
\text { Elementary } \\
\text { School } \\
\text { Principals } \\
\text { Emotional } \\
\text { Intelligence } \\
\text { Leadership } \\
\text { Style And } \\
\text { School } \\
\text { Curlure }\end{array}$ & $\begin{array}{l}\text { Kuantitat } \\
\text { if }\end{array}$ & $\begin{array}{l}\text { Kuesion } \\
\text { er dan } \\
\text { Observa } \\
\text { si }\end{array}$ \\
\hline 18 & $\begin{array}{l}\text { Mbera, } \\
2015\end{array}$ & $\begin{array}{l}\text { Relationshi } \\
p \text { Between } \\
\text { Leadership }\end{array}$ & $\begin{array}{l}\text { Metode } \\
\text { Kuantitat } \\
\text { if }\end{array}$ & $\begin{array}{l}\text { Kuesion } \\
\text { er dan } \\
\text { studi }\end{array}$ \\
\hline
\end{tabular}




\begin{tabular}{|c|c|c|c|c|}
\hline & & $\begin{array}{l}\text { Style used } \\
\text { by Head } \\
\text { teachers of } \\
\text { Public } \\
\text { Secondary } \\
\text { School and } \\
\text { Student } \\
\text { Academic } \\
\text { Performanc } \\
\text { e }\end{array}$ & & $\begin{array}{l}\text { dokume } \\
\text { ntasi }\end{array}$ \\
\hline 19 & $\begin{array}{l}\text { Engin, } \\
2015\end{array}$ & $\begin{array}{l}\text { The effect } \\
\text { of } \\
\text { educational } \\
\text { leadership } \\
\text { on } \\
\text { students' } \\
\text { achieveme } \\
\text { nt: } \\
\text { a meta- } \\
\text { analysis } \\
\text { study }\end{array}$ & $\begin{array}{l}\text { Metode } \\
\text { literatur }\end{array}$ & Artikel \\
\hline 20 & $\begin{array}{l}\text { Christop } \\
\text { her, } \\
2016\end{array}$ & $\begin{array}{l}\text { The Impact } \\
\text { of } \\
\text { Leadership } \\
\text { on Student } \\
\text { Outcomes: } \\
\text { How } \\
\text { Successful } \\
\text { School } \\
\text { Leaders } \\
\text { Use } \\
\text { Transforma } \\
\text { tional and } \\
\text { Instructiona } \\
\text { I Strategies } \\
\text { to Make a } \\
\text { Difference }\end{array}$ & $\begin{array}{l}\text { Metode } \\
\text { kuantitati } \\
f \quad \text { dan } \\
\text { Kualitatif }\end{array}$ & $\begin{array}{l}\text { Wawanc } \\
\text { ara dan } \\
\text { kuesione } \\
r\end{array}$ \\
\hline
\end{tabular}

\section{HASIL DAN PEMBAHASAN Hasil}

Hasil kali ini mengkaji isi dari setiap jurnal yang telah dipilih dengan menggunakan studi literatur yang nantinya dapat memberikan masukan yang dilakukan terkait judul yang dipilih penulis.

Berdasarkan dari hasil penelitian yang dilakukan oleh Hyeo, Young. (2020) mengatakan bahwa kepemimpinan guru adalah variabel yang sangat penting dalam membuat prestasi siswa meningkat. Hal ini membuat pihak sekolah sangat memperhatikan keadaan guru yang mengajar dan juga mengajak guru dalam mendiskusikan keadaan sekolah yang dapat mempengaruhi keadaan guru agar tetap semangat dan profesional dalam bekerja.

Hasil penelitian dari Nurman, dkk (2018) dengan menggunakan metode pendekatan kuantitatif menunjukkan kepemimpinan kepala sekolah SMP Negeri di Kecamatan Bumiayu dikategorikan partisipatif. Karena kepala sekolah dan guru secara bersama-sama memberikan kontribusi dalam menjelaskan fluktuasi variabel mutu sekolah.

Hasil penelitian dari Alil, dkk (2016),yang dilakukan secara kuantitatif dan kualitatif pada kepemimpinan partisipatif kepala sekolah terhadap kinerja guru SMP Negeri di Kota Mataram menghasilkan pengaruh yang besar $(20,1 \%)$. Sehingga sekolah mampu melakukan kepemimpinan bersifat partisipatif melibatkan anggota tim dalam pembuatan keputusan dan memberikan kesempatan bawahan untuk berpartisipasi dalam meningkatkan kinerja guru.

Hasil penelitian Tarhid, (2017) dengan metode litaratur artikel menyatakan bahwa guru profesional yaitu guru yang kepribadiannya stabil, dewasa, arif dan berwibawa. Dalam pendidikan, seorang guru adalah seorang pendidik, pembimbing, pelatih, dan pemimpin yang dapat menciptakan iklim belajar yang menarik, memberi rasa aman, nyaman dan kondusif dalam kelas bagi siswasiswi.

Hasil penelitian Sipayung, (2018) dengan menggunakan penelitian kualitatif dan kuantitatif menggunakan metode wawancara dan kuesioner, menunjukkan bahwa gaya partisipatif sangat dominan digunakan di SMA ST Maria Medan, karena terdapat hubungan positif dan kuat pengaruh keterbukaan kepala sekolah dengan guru dan karyawan sekolah. Gaya kepemimpinan yang dijalani juga dengan menempatkan diri kepala sekolah bukan sebagai orang yang dilayani akan tetapi sebagai pelayan (servant leadership).

Hasil penelitian dari Winarsih (2018) dengan menggunakan metode literatur menyatakan bahwa untuk meningkatkan profesionalisme pemimpin, pemimpin harus bisa memberikan contoh/teladan yang baik dari orang-orang yang dipimpin dan menempatkan sesuai dengan bidangnya yang cocok. dan juga mengajak bawahan untuk bersikusi bersama untuk mencapai tujuan yang dikehendaki.

Hasil penelitian dari Putri (2019) dengan menggunakan metode literatur menyatakan bahwa untuk meningkatkan profesionalisme guru harus memiliki wawasan dan pandangan baru yakni mengandung ide-ide pokok seperti menggalakkan pertumbuhan profesionalisme guru, mengembangkan kepemimpinan 
demokratis, serta memecahkan berbagai masalah yang berkaitan dengan efektivitas proses belajar-mengajar. Oleh karena itu supervisi pendidikan sangat penting untuk meningkatkan mutu pendidikan.

Hasil dari penelitian Septiani (2019) adalah metode penelitian menggunakan studi literatur menghasilkan kepemimpinan yang partisipatif yang dominan karena kepemimpinan kepala sekolah yang efektif memberikan kesejahteraan lahir batin mengembangkan kekeluargaan yang baik, meningkatkan rasa kebersamaan dalam mencapai tujuan dan menumbuhkan budaya positif yang kuat di lingkungan sekolah.

Hasil penelitian dari Arum (2007) dengan metode penelitian studi literatur mengatakan bahwa untuk menghasilkan guru yang profesional harus memiliki kompetensi keguruan. Karena guru mempunyai peranan sangat penting untuk mencerdaskan kehidupan bangsa dan menghadapi tantangan kehidupan.

Hasil penelitian dari Naim, (2017) mengatakan bahwa profesionalisme guru merupakan salah satu faktor penting yang sangat dibutuhkan oleh sekolah untuk menghasilkan lulusan yang baik. Kepala sekolah memiliki tugas untuk mencari guru profesional yang dapat meningkatkan lulusan terbaik. Kepala sekolah berembuk dengan guru dan staff kependidikan lainnya untuk meningkatkan kinerja sekolah yang lebih baik.

Hasil penelitian dari Puspiani (2017) dengan menggunakan pendekatan kualitatif menghasilkan kepala sekolah dalam meningkatkan profesionalisme guru fiqih di Madrasah Ibtidaiyah Darul Fikri dilaksanakan melalui sharing antar guru dan kepala sekolah dilakukan kegiatan pelatihan-pelatihan, rapat antara bawahan dan atasan untuk mendiskusikan suatu masalah, sharing antar sekolah. Kendala yang dialami yaitu kurangnya pengetahuan dan kurangnya kerjasama antar guru fiqih.

Hasil penelitian dari Ruslan (2020) dengan menggunakan metode kuantitatif diperoleh hasil yang menunjukkan bahwa keberhasilan atau kegagalan sekolah dalam menampilkan guru profesionalisme sangat tergantung pada kualitas gaya kepemimpinan yang digunakan oleh kepala sekolah dan guru. Ini secara langsung mempengaruhi kinerja guru dan profesi guru. Peningkatan profesionalisme guru didukung oleh keterampilan dan kinerja guru sendiri yang tidak terpisahkan dari perilaku kepemimpinan situasional dari kepala sekolah. Baik kepala sekolah selalu memperhatikan pengetahuan keterampilan guru dalam pekerjaannya, karena kinerja guru adalah tanggung jawab sekolah.

Hasil penelitian Gadusova (2019) menunjukkan untuk meningkatkan efisiensi pendidikan adalah keterampilan profesional guru dan evaluasinya. Kontribusi ilmiah yang mendasari dari proyek ini adalah metodologi baru yang mapan untuk pendekatan inovatif untuk mengevaluasi pekerjaan guru dan kompetensi mereka. Berdasarkan pada penetrasi opini dan evaluasi sikap kedua agen, evaluator dan guru yang dievaluasi, mengikuti ide tersebut peningkatan kualitas proses pendidikan dalam konteks kebutuhan dan kunci yang diperlukan kompetensi pelajar.

Hasil penelitian Gultom (2018) menunjukkan ada pengaruh antara gaya kepemimpinan demokratis dan gaya kepimpinan partisipatif. Yang dapat memiliki pengaruh prositif pada sekolah dan memberikan motivasi kerja guru.

Hasil penelitian dari Burhanudin (2017) menghasilkan bahwa kepala sekolah dalam mengembangkan profesionalisme guru untuk mencapai kualitas pendidikan yang lebih baik. Dapat disimpulkan bahwa pengawasan peran kepala sekolah harus mengembangkan profesionalisme guru dengan cara aktif mengikuti konferensi, kursus, pelatihan atau lokakarya.

Hasil penelitian dari Suhanji (2016) menunjukkan pengembangan profesionalisme guru sebagai tenaga pendidikan dan pembelajar dalam persekolahan yaitu kinerja guru yang profesional. Tingkat penguasaan guru terhadap bahan pelajaran dan penguasaan struktur konsep-konsep keilmuannya, pemahaman guru terhadap seorang siswa. Guru perlu diberdayakan seoptimal mungkin agar kinerjanya meningkat.

Hasil penelitian dari Segredo (2014) menunjukkan pemimpin sekolah yang efektif membangun nilai-nilai dan mendekati komitmen mereka terhadap peningkatan sekolah dengan moral. Kepala sekolah seharusnya tidak membatasi ruang lingkup guru dan karyawan untuk hanya berfokus pada kebutuhan sekolah.

Hasil penelitian dari Mbera (2015) menunjukkan pemimpin yang baik karena sifatsifat yang mereka miliki seperti kecerdasan, penampilan dan kemampuan bahasa. Tugas 
utama kepala sekolah adalah membantu menciptakan pekerjaan yang sehat lingkungan di mana siswa senang dan siap untuk belajar dan guru mengidentifikasi diri dengan misi dan tujuan sekolah.

Hasil penelian dari Karadag, dkk, (2015) menunjukkan bahwa kepemimpinan pendidikan memiliki efek sedang pada prestasi siswa. Seperti sebelumnya diharapkan efek paling komprehensif di antara gaya kepemimpinan ditemukan dalam kepemimpinan distributif dan transformasional.

Mempertimbangkan pengaruh kepemimpinan pendidikan pada prestasi siswa, disarankan untuk memeriksa pengaruh kepemimpinan terhadap komponen sekolah lainnya dan pemegang saham dalam studi masa selanjutnya.

Hasil penelitian Christopher, dkk (2016) menunjukkan bahwa kemampuan sekolah untuk meningkat dan berkelanjutan keefektifan dalam jangka panjang terutama bukan hasil dari gaya kepemimpinan kepala sekolah tetapi dari pemahaman dan diagnosis kebutuhan sekolah dan penerapan pendidikan yang diartikulasikan secara jelas dan diorganisasi secara organisasi nilai melalui berbagai kombinasi dan akumulasi waktu dan konteks strategi sensitif yang "berlapis" dan semakin tertanam dalam pekerjaan sekolah, budaya, dan prestasi.

\section{Pembahasan}

Berdasarkan penelitian di atas, memiliki banyak kesamaan berkaitan dengan kepemimpinan partisipatif dalam upaya meningkatkan profesionalisme guru. Dengan memperhatikan penelitian-penelitian di atas gaya yang dipilih kepala sekolah berpandangan kepemimpinan harus memberi strategi, pola komunikasi daam melaksanakan kemimpinan untuk meningkatkan profesionalisme guru (Nurman, dkk, 2018).

\section{Peran Kepala Sekolah}

Kepala sekolah merupakan seorang pemimpin di dalam suatu organisasi atau lembaga. Sedangkan sekolah dapat diartikan sebuah lembaga atau tempat menerima dan memberi pelajaran. Maka kepala sekolah dapat diartikan sebagai seorang tenaga profesional guru yang diberi tugas untuk memimpin suatu sekolah di mana diselenggarakan proses pembelajaran dan untuk mencapai tujuan yang diinginkan bersama. Kepala sekolah harus mempunyai kemampuan untuk memimpin lembaga, membimbing guru, membimbing tenaga kependidikan non guru, membimbing siswa dan memberi contoh mengajar untuk mencapai tujuan (Mulyasa, 2006). Kepala sekolah harus mempunyai strategi untuk meningkatkan profesionalisme guru di sekolah. Kemampuan yang harus diwujudkan kepala sekolah sebagai leader dapat dianalisis dari kepribadian, pengetahuan terhadap tenaga kependidikan, visi dan misi sekolah, kemampuan mengambil keputusan, dan kemampuan berkomunikasi

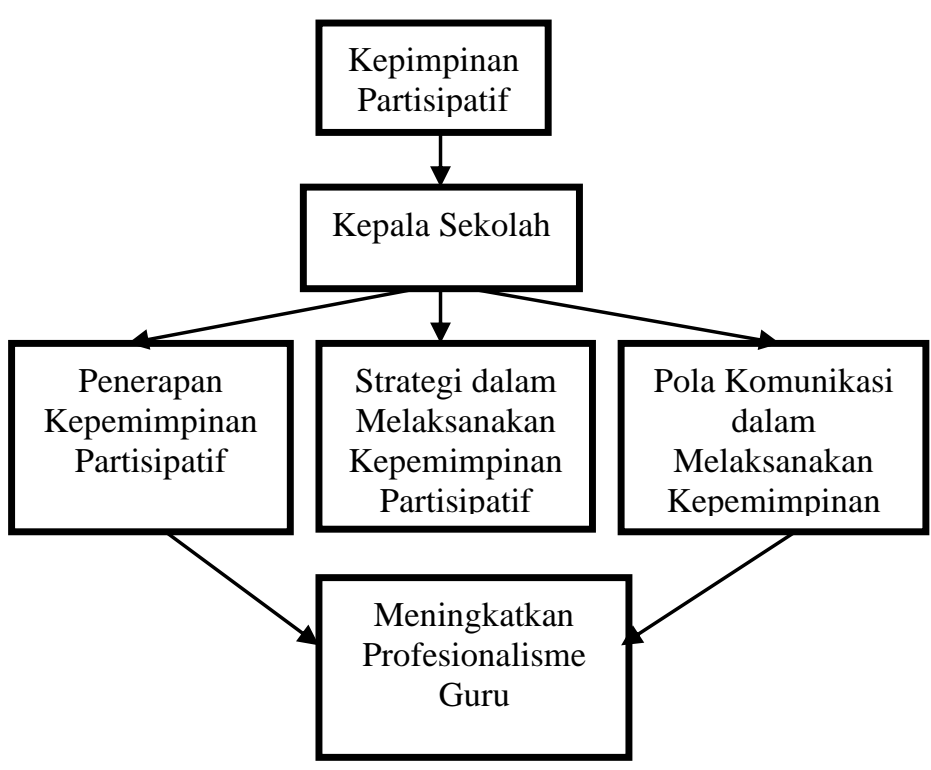

Gambar 1. Kepemimpinan Partisipatif

\section{Penerapan, Strategi dan Pola komunikasi dalam Kepemimpinan Partisipatif}

Kepemimpinan partisipatif mempunyai manfaat terhadap peningkatan mutu lembaga pendidikan yang kualitas keputusannya lebih tinggi, penerimaan keputusan yang lebih tinggi oleh partisipan dan pengembangan keterampilan pembuatan keputusan. Kepemimpinan partisipatif kepala sekolah dapat mencapai sasarannya diantaranya adalah :

a. Keputusan yang diambil menjadi lebih tinggi karena adanya kegiatan musyawarah.

b. Guru dan karyawan diperlakukan secara terhormat sehingga merasa ikut memiliki sekolah.

c. Komitmen para guru dan karyawan menerapkan keputusan menjadi lebih tinggi bila dilakukan dengan diskusi bersama

Sehingga kepemimpinan yang partisipatif, diharapkan membuat lembaga atau sekolah menjadi lebih baik karena terdapat diskusi 
bersama antara atasan dan bawahan untuk mencapai tujuan bersama.

Strategi dan komunikasi yang diberikan untuk meningkatkan kepemimpinan partisipatif dengan cara memberikan penghargaan, pemberian insentif dan perhatian. Untuk meningkatkan mutu guru, kepala sekolah mengikutsertakan guru dalam berbagai kegiatan seperti pelatihan, seminar, diskusi, sertifikasi untuk pengembangan karirnya. Komunikasi yang dilakukan oleh kepala sekolah dalah komunikasi dengan pendekatan partisipatif dimana kepala sekolah dan guru aktif dalam suatu kegiatan. Komunikasi yang efektif akan mendorong guru bekerja dengan sungguh-sungguh untuk mencapai tujuan.

\section{Meningkatkan Profesionalisme Guru}

Guru profesional yaitu yang membantu siswa untuk memperoleh pendidikan yang bermutu. Untuk dapat menjadi guru yang profesional, guru mampu menjadi diri yang lebih baik (Sholeh, 2006:9). Kemampuan guru harus ditingkatkan karena dapat mempersaingkan guru lintas negara. Sebagai guru yang profesional harus mengikuti perkembangan profesi dan tuntutan masyarakat untuk menjadi lebih baik. Profesional guru dapat dipenuhi dengan cara memahami tuntutan standar profesi, mencapai kualifikasi, dan membangun hubungan yang baik lewat organisasi profesi. Guru yang profesional yaitu guru yang dapat menguasai materi pembelajaran, dan membimbing peserta didik untuk menjadi yang lebih baik.

\section{PENUTUP \\ Kesimpulan}

Dari beberapa jurnal yang sudah dikaji dengan metode studi literatur yang membahas tentang gaya kepemimpinan partisipatif dalam upaya meningkatkan profesionalisme guru maka perilaku pemimpin yang partisipatif perlu adanya saran dari bawahan dalam proses pengambilan keputusan. Yang artinya bawahan merasa lebih dihargai oleh atasannya karena mereka dianggap mampu ikut serta dalam pengambilan keputusan untuk meningkatkan kinerja sekolah semakin meningkat dan juga melatih keprofesionalan. Dengan gaya kepemimpinan partisipatif, keyakinan seorang pemimpin terhadap kemampuan bawahannya akan saling berhubungan.

\section{Saran}

1. Kepala sekolah diharapkan lebih mendengarkan ide guru dan bawahan untuk mebuat suasana sekolah menjadi aman, nyaman dan memiliki terhadap upaya meningkatkan kinerja sekolah.

2. Kepala sekolah diharapkan berupaya meningkatkan kinerja guru dengan memberikan perhatian baik dari segi materi maupun non materi.

3. Kepala dinas pendidikan diharapkan dapat memberikan prasarana untuk meningkatkan profesionalisme guru

4. Kepala sekolah diharapkan lebih banyak mengikutsertakan guru dan karyawan dalam program pendidikan dan pelatihan yang diselenggarakan oleh dinas pendidikan maupun diluar itu untuk meningkatkan pengetahuan dan keterampilan, sehingga kemampuan dalam mengambil suatu keputusan atau tindakan menjadi lebih baik.

5. Kepada para tenaga pendidik diharapkan untuk meningkatkan kinerja tenaga pendidik dalam menjalankan tugasnya

6. Pada peneliti-penelitian lain diharapkan dapat melakukan penelitian dengan pendekatan yang berbeda agar menambah wawasan mengenai gaya partisipatif meningkatkan profesionalisme guru.

\section{DAFTAR PUSTAKA}

Arum, W. S. A. (2007). Upaya Meningkatkan Profesionalisme Guru Berlandaskan IImu Pendidikan Dalam. Jurnal Perspektif IImu Pendidikan. Vol 16. Universitas Negeri Jakarta. https://doi.org/10.21009/pip.162.10

Bali, S. K. (2016). Profesionalisme Guru Dalam Upaya Meningkatkan Mutu Pembelajaran. Jurnal Penjamin Mutu. $\begin{array}{lll}\text { Vol.2 No.2 } & \text { Bali } \\ \text { https://doi.org/10.25078/jpm.v2i2.73 }\end{array}$

Burhanudin, M. (2017). The Roles of Pricipals in Increasing Education Quality By Developing Teacher Profesionalism. Journal Didaktika Religia Vol 5. No.1. Stain Kediri https://doi.org/10.30762/didaktika.v5i1.8 $\underline{56}$ 
Christopher, D., Qing, G., \& Pam, S. (2016). The Impact of Leadership on Student Outcomes: How Successful School Leaders Use Transformational and Instructional Strategies to Make a Difference. Jurnal Administrasi Pendidikan Triwulanan. Vol. 52 (2) 221 258

https://doi.org/10.1177/0013161×156168 $\underline{63}$

Karadag, E., Bektas, F., Cogaltay, N., \& Yalcin, M. (2015). The effect of educational leadership on students' achievement: a meta-analysis study. Jurnal Educ Asia Pasifik. Vol. 16: 79-93 https://doi.org/10.1007/s12564-015 9357-x

Gadusova, Z. (2019). Teacher's Professional Competence and Their Evaluatin. Journal Education and Self Development Vol 14 No.3. Doi: 10.26907/esd14.3.02.

Gultom, A. (2018). Effect of Demo Leadership Style and Bureaucratic Leadership Style against Teacher Work Motivation in Dolok Batu Naggar State 1 State School. Science and Technology Publications, Lda.

https://doi.org/10.5220/00094947030603 $\underline{13}$

Heriyansyah. (2018). Guru Adalah Manajer Sesungguhnya Di Sekolah. Jurnal Manajemen Pendidikan Islam. Islamic Management Vol.1 No.1: Bogor. https://doi.org/10.31227/osf.io/kjve8

Mbera, A. (2015). Relationship Between Leadership Style used by Head Teachers of Public Secondary Schools and Students Academic Performance. International Journal of Academic Research in Business and Social Sciences. https://doi.org/10.6007/ijarbss/v5-i7/1733
Mulyasa, E. (2015). Manajemen \& Kepemimpinan Kepala Sekolah. Jakarta: PT Bumi Aksara.

Mulyasa, E. (2006). Menjadi Kepala Sekolah Profesional. Cetakan VI. Bandung: Remaja Rosdakarya.

Naim, A. (2017). Profesionalisme Kepemimpinan Kepala Sekolah dan Kinerja Guru Dalam Peningkatan Prestasi Belajar Siswa. Jurnal PII Vol 2 No.1. STIT Islamiyah Karya Pembangunan Paron Ngawi.

https://doi.org/10.35316/ipii.v2i1.66

Nurman, M., Yuliejantiningsih, Y., \& Roshayanti, F. (2018). Pengaruh Kepemimpinan Partisipatif Kepala Sekolah Dan Kompetensi Guru Terhadap Mutu Sekolah SMP Negeri Di Kecamatan Bumiayu Kabupaten Brebes. Jurnal Manajemen Pendidikan. Vol 7 No.8. PGRI Semarang https://doi.org/10.26877//mp.v7i3.3141

Pupiani. (2016). Upaya Kepala Sekolah Dalam Meningkatkan Profesionalisme Guru Fiqih Di Madrasah Ibtidaiyah Darul Fikri Tahun 2016- 2017. Jurnal Islamic Education. Fakultas Agama Islam, Universitas Muhammadiyah Ponorogo https://doi.org/10.24269/tarbawi.v1i01.10 $\underline{3}$

Putri, A. R. (2019). Meningkatkan Profesionalisme Guru Sebagai Aktor Utama Dalam Dunia Pendidikan. https://doi.org/10.31227/osf.io/ybxc9

Rahmi, S. (2014). Kepemimpinan transformasional dan budaya organisasi: Ilustrasi di Bidang Pendidikan. Jakarta: Mitra Wacana Media.

Ruslan. (2020). The Influence of Principal's Situational Leadership and Teacher's Professionalism on Teacher's Performance. International Journal of Progressive Sciences and Technologies 
(IJPSAT). Vol $20 \quad$ No.1 Yukl, G. (2015). Kepemimpinan dalam https://doi.org/10.31219/osf.io/t7cha $\quad$ organisasi. PT Indeks.

Segredo, M. R. (2014). The Relationships Between Elementary School Principals Emotional Intelligence, Leadership Style and School Culture Journal Educational Administrationand Supervision. Florida International University.

DOI:10.25148/etd.FI14071124

Septiani, N. (2019). Gaya Kepemimpinan Pendidikan. Univessitas Negeri Padang https://doi.org/10.31227/osf.io/car7d

Sipayung, R. (2018). Pengaruh Gaya Kepemimpinan Kepala Sekolah Dalam Meningkatkan Kreativitas Guru Di SMA ST. Maria Medan. School Education Journal. Vol 8 No.2. Universitas Katolik Santo Thomas. https://doi.org/10.24114/seipgsd.v8i2.98 $\underline{29}$

Suhanji. (2016). Synergy of Teacher Profesionalism Development of The Quality of Education. International Conference of Moslem Society ISSN 2622-5840, Volume 1, 2016, Pages 1-12. DOI:

https://doi.org/10.24090/icms.2016.1812

Tarhid. (2017). Kepemimpinan Kepala Sekolah dalam Meningkatkan Profesionalisme Guru. Jurnal Kependidikan IAIN Purwokerto. DOI: https://doi.org/10.24090/jk.v5i2.1931

Thoha, M. (2012). Kepemimpinan Dalam Manajemen. Ed. 1. Jakarta: Rajawali Press.

Undang-undang RI No. 14 Tahun 2005 tentang Guru dan Dosen. Jakarta.

Winarsih, S. (2018). Gaya Kepemimpinan Kepala Sekolah dalam Meningkatkan Kinerja Guru. Jurnal Internasinal Conference Of Moslem Society. UPI Bandung. https://doi.org/10.24090/icms.2018.1864 